\title{
Notas e comentários sobre a dinâmica do comércio Brasil-África nas décadas de 1970 a $1990^{1}$
}

IVO DE SANTANA*

As relações econômicas do Brasil com a África não são recentes. Ao contrário, datam dos primórdios da formação do Estado brasileiro, e seu desenvolvimento é marcado por períodos de descontinuada intensidade. Sua importância, contudo, é relevante para a história do país, sendo ressaltada por diversos estudiosos que enfatizam o papel fundamental desempenhado por essas relações na formação da sociedade e economia do Brasil.

Este artigo tem como propósito discorrer sobre a presença empresarial brasileira na África entre as décadas de 1970 e 1990, enfocando particularmente as visões de diversos autores que se voltaram ao estudo das relações entre o Brasil e África entre as décadas mencionadas, um período de grandes transformações no desenvolvimento desse intercâmbio e, portanto, rico em acontecimentos e experiências. Trata-se, sobretudo, da tentativa do autor em esclarecer indagações pessoais advindas do seu exercício profissional, enquanto servidor público de instituição voltada ao acompanhamento das atividades de comércio exterior. Nesse sentido, o presente texto objetiva responder a duas dessas questões. Primeiramente: sob que motivações o comércio Brasil-África obteve um notável crescimento no período compreendido entre os anos 1970 a 1990? Em segundo lugar: quais as perspectivas que se apresentariam para o empresário brasileiro que desejasse efetuar negócios junto ao mercado africano?

No aprofundamento dessas questões empregou-se como recurso a pesquisa bibliográfica junto a universidades e instituições oficiais brasileiras voltadas para o comércio exterior ${ }^{2}$. Além disso, foram de importante significado os depoimentos colhidos junto a executivos envolvidos em operações comerciais no mercado africano e especialistas em comércio exterior.

De imediato, constatou-se que abordar temas que envolvem as relações comerciais entre o Brasil e a África é tarefa complexa, considerando-se que não são apenas os Estados que estão em causa, mas também os povos e os interesses

Rev. Bras. Polít. Int. 46 (2): 113-137 [2003]

* Analista do Banco Central do Brasil e mestre em Administração e Comércio Internacional pela Universidad de Extremadura, Espanha. E-mail: ivo.santana@bcb.gov.br. 
dos agentes econômicos, determinando circunstâncias históricas e também momentos distintos. Esse parece ser o entendimento de Renouvin (citado por Almeida, 1998, p. 22) ao afirmar que "estudar as influências que se exercem sobre as relações internacionais deixando de lado o conjunto de circunstâncias de um momento ou de uma época seria falsear a perspectiva histórica”. Dessa forma, perseguindo uma visão mais ampla das relações econômicas Brasil-África acreditase ser oportuno tecer algumas considerações acerca de fatores políticos e econômicos que influenciaram o comportamento empresarial brasileiro nas suas relações com o continente africano desde 1961, ano que representa um referencial importante na reaproximação do país ao continente africano.

\section{A estratégia da substituição de importações e as relações Sul-Sul}

Ao investigarmos sobre o desenvolvimento de negócios brasileiros no mercado africano, norteamo-nos pela análise do processo de desenvolvimento econômico brasileiro, particularmente a estratégia de substituição de importações, que elegeu a industrialização como elemento-chave para o desenvolvimento e inseriu o país, de forma singular, no contexto das novas relações com o Terceiro Mundo. Trata-se das relações Sul-Sul, no âmbito das quais se incentiva o incremento das trocas entre os países em desenvolvimento, e a partir do qual a África se torna parceira de grande importância para o Brasil.

Assim, partimos da compreensão de que até os anos 1950 a economia brasileira era essencialmente agrária e voltada para a exportação de produtos primários, explorando vantagens comparativas em termos de recursos naturais e de mão-de-obra. Essa condição, segundo os pensadores da Comissão Econômica de Planejamento para a América Latina $(\mathrm{Cepal})^{3}$, configurava um atraso que era preciso romper para se conseguir avançar rumo ao desenvolvimento. De acordo com esse pensamento, sistematizado em obras de Raul Prebisch, Osvaldo Sunkel, Celso Furtado e outros, a reversão desse atraso seria obtida pela afirmação da industrialização como elemento aglutinador e articulador do desenvolvimento, do progresso, da modernidade, da civilização e da democracia política.

Ao longo desses anos, principalmente após a Segunda Guerra Mundial, o país procurou modificar essa situação e, apoiado nas recomendações da Cepal, deu início ao processo de desenvolvimento da indústria nacional. Mediante a intervenção estatal (políticas industrial, comercial e macroeconômica), adotou-se um modelo de desenvolvimento cuja estratégia principal consistia em promover a industrialização, visando substituir grande parte dos produtos importados por produtos fabricados no País. A adoção dessa estratégia garantiu ao Brasil longos períodos de crescimento elevado, mudando substancialmente o seu padrão de comércio. De economia primário-exportadora, o Brasil se tornou importante exportador de produtos manufaturados, não somente em termos regionais, mas 
igualmente em âmbito mundial. Essa mudança se deu de forma gradual, começando pela eliminação dos bens de consumo não-duráveis ${ }^{4}$ da agenda de exportações (Pinheiro \& Moreira, 1997).

A substituição de importações avançou, alcançando os bens de consumo duráveis, com ênfase nos automóveis. Os bens intermediários foram também afetados e, numa última etapa, na década de 1960, teve início a substituição dos bens de capital ${ }^{5}$. A partir dessa fase, o país experimenta um elevado crescimento industrial, que passou a exigir um mercado de amplas dimensões para assegurar os benefícios da escala de produção. Mas a crescente inflação dos anos 1960 deteriorou o poder de compra da classe assalariada. Aliada a isso, ocorre uma queda no volume de emprego, ocasionando substancial redução no volume de demanda interna. Aumenta desse modo a capacidade ociosa da maioria dos setores, tanto quanto a acumulação de estoques invendáveis, o que vai levar à procura por mercados externos como meio de permitir às empresas desfazer-se de parte desses estoques.

Com a adoção do Paeg (Plano de Ação Econômica do Governo) em 1967, o Governo Costa e Silva inicia um processo que tem como objetivo básico o desenvolvimento econômico e social do país, passando a executar uma política de facilitação das exportações por meio do estabelecimento de isenções fiscais e da abertura de linhas de crédito. Em 1968, essa política continua, acrescida da minidesvalorização do câmbio (Alves, Sayad, 1987).

Esse era o quadro brasileiro quando a economia mundial entrou em crise, ao final dos anos 1960. Os países industrializados registram os primeiros sinais de desaceleração ${ }^{6}$ e passam a impor fortes restrições às exportações do Terceiro Mundo, levando a sérios impasses na condução do diálogo entre as nações do Norte, industrializadas, e do Sul, em desenvolvimento (Cunha, 1991). Nessa conjuntura, a rígida bipolaridade do pós-guerra é substituída por certa flexibilidade nos vínculos interestatais e, apesar de os centros de poder estarem quase exclusivamente no Norte, essa flexibilidade permite o surgimento de uma multipolaridade na área econômico-industrial. Os países do Sul adquirem grande importância como produtores de matérias-primas, como o petróleo, e passam a reivindicar a reforma do sistema econômico mundial como meio de atenuar a situação cada vez mais crítica em que se encontravam.

Frente à falta de soluções satisfatórias e também paralelamente a essas reivindicações, fortalece-se no Terceiro Mundo a idéia de que os problemas de desenvolvimento não seriam solucionados exclusivamente com a ajuda dos países desenvolvidos. Inicia-se então um movimento de valorização da cooperação horizontal, em nível regional e intra-regional, entre os países do Sul. Tratava-se de um movimento que buscava dar ênfase ao esforço próprio e à colaboração recíproca entre os países do Sul. Estimava-se que uma ação conjunta pudesse aumentar o poder de negociação das nações em desenvolvimento frente aos países 
industrializados (Perona, 1985). Essa percepção encontra uma quase unanimidade no seio do Terceiro Mundo, como atestam as numerosas conferências internacionais realizadas sobre o assunto após a VI Sessão Extraordinária da Assembléia das Nações Unidas, em 1972, que pleiteava a instauração de uma nova ordem econômica mundial.

A premissa básica partia da consideração de que, num sistema de sujeição global controlado pelas nações desenvolvidas, o reforço dos laços econômicos entre os países do Sul se constituiria em elemento fundamental da estratégia de desenvolvimento do Terceiro Mundo, sendo necessário criarem-se condições para o estabelecimento de novas relações de força em nível internacional. Conhecidas na literatura econômica como relações Sul-Sul, estas iriam converter-se não apenas em fonte de interdependência como também em instrumento de pressão, no quadro da reestruturação da economia mundial, e ainda em via de transferência de riqueza entre os países do Terceiro Mundo.

O movimento Sul-Sul se propaga. Interliga-se com o Movimento dos NãoAlinhados ${ }^{7}$, com o Grupo dos 77 e com a Organização dos Países Exportadores de Petróleo (Opep), que apóiam essa nova estratégia de esforço coletivo para reduzir a influência das grandes potências no sistema internacional (Ogwu, 1976). Com o crescimento dessa tendência, chegou-se a propor o estabelecimento de uma associação Sul-Sul de Estados em via de desenvolvimento (Duarte, 1984).

Para d'Adesky (1985), esse movimento engendra duas concepções. A primeira, em sentido amplo, refere-se ao sistema de trocas dependentes entre o Norte e o Sul, cuja estrutura fixa é o alvo das críticas dos países em desenvolvimento nas negociações internacionais. A segunda, em nível específico, ocupa-se das relações particulares entre países do Terceiro Mundo, no propósito de que os esforços coletivos possam redundar em um desenvolvimento econômico e tecnológico que contribua para produzir uma ruptura no circuito das relações centroperiferia. A idéia de ruptura, todavia, não é compartilhada por Selcher (1984), que entende a cooperação Sul-Sul como um relacionamento "horizontal" que intenta servir como alternativa, e não como substituição total, às relações "verticais" de dependência com o Norte desenvolvido.

Integrando-se à corrente reivindicatória terceiro-mundista, o Brasil passa a fazer, nos fóruns de que participa, críticas constantes à deterioração das trocas internacionais, ao monopólio e às medidas protecionistas adotadas pelos países industrializados. Essa postura avança ostensivamente a partir do reforço da identidade terceiro-mundista assumida pelo país, que passa inclusive a defender posições consideradas, por setores da opinião pública, como de relativa imprudência (Saraiva, 1999) ${ }^{8}$. Vale ressaltar que diversos países latino-americanos demonstraram interesse por mercados periféricos fora de sua área, sendo o Brasil aquele em que essa tendência foi mais acentuada. Exemplo disso é o aumento do 
volume de comércio entre o Brasil e a Nigéria, que, de US\$ 25 milhões em 1972, passa para US\$ 600 milhões em 1978.

Para Calcagnoto (1985), a "abertura ao Sul” efetuada pelo Brasil vai consolidar-se em três fases distintas. Abre-se numa primeira fase com a viagem do chanceler Gibson Barbosa a nove países africanos, em 1972, promovendo a aproximação diplomática com nações recém-emancipadas ou ainda em processo de luta anticolonial. Na segunda fase, de 1974 a 1978, a abertura continua, com a condenação dos regimes colonialistas e racistas na África, bem como o reconhecimento da OLP. Na terceira fase, a partir de 1979, ela se torna ainda mais nítida quando o Brasil passa a se definir explicitamente como país terceiromundista.

De fato, embora no Governo Costa e Silva (1967-9) algumas vozes se tenham manifestado em prol dessa abertura, é a partir de 1972 que se observa uma incisiva postura de ampliação do relacionamento do Brasil com os países do Sul, especialmente os do continente africano, que à época tinha um lugar de destaque nas trocas do Terceiro Mundo. Tratava-se de uma região de grandes potencialidades, com um mercado expressivo e detentora de importantes reservas de petróleo, além de outras matérias-primas. Para o Brasil, o mercado de consumo africano, que se imaginava de grande relevância, passou a ter importância estratégica na política de intensificação das exportações, originada não apenas da necessidade de aumentar o valor destas e de contribuir para o equilíbrio do balanço de pagamentos, mas também da pragmática deliberação de ampliar as fontes de aprovisionamento externo do país em face de uma situação mundial particularmente complexa, sobretudo depois da crise petrolífera de 1973.

A África, por sua vez, na busca da autonomia e de melhorar sua posição perante as ex-metrópoles coloniais européias e os centros do capitalismo mundial, intensifica a procura de novos investidores e parceiros comerciais. Nesse contexto, volta-se para os países recém-industrializados do Terceiro Mundo - entre eles, como um dos parceiros privilegiados, o Brasil. A relativa expansão econômica africana, advinda do boom do petróleo, tornava conveniente uma parceria comercial e estratégica, no âmbito do Atlântico, com um país que oferecia uma tecnologia dita "tropical”, adaptada às circunstâncias africanas. Assim, ampliar o intercâmbio favoreceria a conjugação de interesses mútuos: as nações africanas, fontes importantes de petróleo, buscavam diminuir sua dependência econômica em relação ao Norte, e o Brasil, carente dessa matéria-prima, tinha bens e serviços adequados a oferecer ${ }^{9}$. Além disso, para o governo brasileiro, as relações com a África abriam a possibilidade de reforçar o perfil externo do país nos fóruns multilaterais e no jogo diplomático global, pois, falando como representante do Terceiro Mundo, o Brasil teria muito mais peso do que falando isoladamente (Sardenberg, 1980; Lafer, 1984). 
Entretanto, ainda que esse movimento das exportações brasileiras em direção à África possa representar uma alternativa ao mercado dos países industrializados do Norte, não deve ser percebido unicamente como tal. Não se pode esquecer que esse movimento visa também responder às necessidades do desenvolvimento da acumulação capitalista implementada internamente no Brasil, no sentido de realizar a mais-valia das indústrias aqui localizadas. Nessa condição, os contatos com o Hemisfério Sul gradativamente assumem formas em que o Brasil aparece como fornecedor de produtos manufaturados e semimanufaturados, recebendo em troca produtos primários. No decorrer da segunda metade dos anos 1970, progressivamente, ganham destaque as operações de venda de tecnologia e de serviços - em particular, nas áreas de engenharia civil, projetos ferroviários, usinas de açúcar e álcool, como também engenharia de detalhes de unidades industriais (Fragoso, 1984; Calcagnoto, 1985) ${ }^{10}$.

A viabilização dessas operações foi tornada possível a partir de uma grande ofensiva brasileira envolvendo diplomacia, agências de governo e empresas estatais. Entrelaçadas num projeto comercial, essas instituições orientaram-se para um efetivo apoio a empresas multinacionais com filiais no Brasil e a empresas de capital industrial nacional, estimulando-as a estabelecer relações comerciais com o continente africano. As empresas tiveram à sua disposição todo um aparato estatal que foi de significativa importância na promoção de eventos ${ }^{11}$, bem como na condução do processo de comercialização e na luta para vencer os obstáculos surgidos nesse processo.

Nesse sentido, o governo brasileiro empenhou-se na redução de barreiras e dificuldades enfrentadas pelas empresas nacionais na concorrência com estrangeiras, sobretudo as das antigas metrópoles coloniais européias, já de há muito estabelecidas nas regiões em pauta. Esse empenho foi fundamental na solução de problemas relacionados ao desconhecimento mútuo entre o Brasil e as nações africanas; bem como à preferência dos consumidores desses países pelas empresas e produtos europeus. Além desses, podem-se citar problemas como a adoção de práticas indevidas - protecionismo, subsídios e reservas de mercado em detrimento de empresas brasileiras -, bem como a insuficiência nos mecanismos fiscais, de crédito, de seguros e de câmbio (Pimentel, 2000). A extensão desse apoio brasileiro pode ser avaliada pela análise da gama de incentivos à exportação, incluindo tanto os permitidos pelo Gatt ${ }^{12}$, como a dispensa de pagamentos fiscais ou tarifas, quanto os não-permitidos, como os subsídios fiscais. Com isso se obteve uma ampla margem de folga para a formação dos preços de exportação, que se reduziram a valores situados entre $40 \%$ a $50 \%$ abaixo dos preços do mercado interno (Calcagnoto, 1985).

Ao longo da década de 1980, o desempenho da economia brasileira sofreu um declínio. A inflação, que se havia acelerado na década de setenta, chegou ao final dos anos 1980 praticamente fora de controle, enquanto o PIB crescia em 
níveis mínimos (em média, 1,3\% a.a.), abaixo do crescimento demográfico, que era de 1,9\% a.a. Com o endividamento crescente do Estado, o déficit público se elevou e a economia entrou em processo de estagnação (Pinheiro \& Moreira, 1977) ${ }^{13}$. O regime de incentivos criado para fomentar a substituição de importações exercia notável influência sobre o fraco desempenho da economia brasileira nesse período: à medida que se esgotavam as possibilidades de substituição de importações, esse regime deixava de ser um fator de promoção, transformandose em obstáculo ao crescimento econômico. O excesso de intervenção estatal na alocação de recursos, especialmente a proteção e os subsídios à indústria local, levava a uma série de distorções nos mercados de produtos e fatores que acabavam por impactar negativamente o crescimento econômico. Diante desse quadro, adotase, na segunda metade da década de 1980, uma política de liberalização comercial e de redução da intervenção estatal na alocação de recursos. A partir de 1988, o governo vai progressivamente abandonando o regime de incentivos adotado durante a industrialização, e com isso se reduz a proteção aos produtos domésticos. Em 1989, a tarifa média de impostos sobre importações era de 51\%; no segundo semestre de 1993, ela caíra para $14,9 \%$. Nesse ano, já se havia eliminado a maior parte das barreiras tarifárias às importações.

A política de liberalização comercial acaba por levar a modificações no padrão de comércio formado durante os anos de substituição de importações, sendo significativa para os bens de consumo. Em setores como têxteis, vestuário e calçados, mobiliários e equipamentos de transporte, as tarifas aduaneiras, que estavam acima de $100 \%$, caíram para cerca de $20 \%$ em 1993. Sob a influência da “ortodoxia neoliberal”, a intervenção estatal cede lugar à orientação do mercado. Assim, subsídios e incentivos à exportação são reduzidos ou eliminados - de uma média de 3,1\% do PIB em 1981-4, o valor desses incentivos cai para 1,3\% em 1990. Em resultado disso, as relações Sul-Sul entram em declínio. As novas prioridades do comércio exportador brasileiro a partir do final dos anos 1980 apontam quase que exclusivamente para parceiros tradicionais, como os Estados Unidos, a União Européia e o Japão, que ampliam substancialmente sua participação no comércio bilateral com o Brasil. A evolução do Mercosul, constituído em 1991, aumenta a participação da América Latina nesse comércio, incentivada por fatores como proximidade geográfica, melhores possibilidades de coordenação e apoio, maior suporte do governo brasileiro, proximidade de idioma e de cultura. A participação do continente africano nas exportações brasileiras reduz-se significativamente, estagnando a partir dos anos 1990.

\section{Incentivos à exportação}

O governo brasileiro oferecia muitos incentivos para estimular as exportações para o continente africano. A título de exemplo, podemos citar o 
Befiex $^{14}$, programa especial de incentivos que beneficiava as empresas nacionais e estrangeiras que se instalassem no Brasil com o fito de exportar sua produção. Esse mecanismo foi amplamente utilizado pelas companhias multinacionais, que recebiam generosas taxas, de 15 a 25\%, como estímulo às exportações. Em 1977, a Volkswagen do Brasil iniciou a exportação de carros para a Nigéria e Angola, estabelecendo, depois, montadoras nesses países. A IBM do Brasil foi outra empresa que desenvolveu ação semelhante, beneficiando-se desse e de outros incentivos (Uriarte, citado por Saraiva, 1999, p. 148).

Por sua vez, o programa Finex do Banco Central concedia recursos a taxas privilegiadas de financiamento para fazer face às despesas relativas às diferentes etapas de fabricação de bens indiretos, manufaturados e semimanufaturados. Isso permitiu a viabilização de muitos negócios em condições compatíveis de igualdade com parceiros tradicionais dos africanos, como era o caso das ex-metrópoles, cujos acordos preferenciais de comércio inviabilizavam a comercialização das manufaturas brasileiras, já penalizadas por diferentes obstáculos, dentre eles os decorrentes das insuficientes rotas de transportes, assim como dos fretes caros e difíceis.

Numa época de baixo crescimento da economia mundial, notabilizava-se o esforço do Itamaraty, tentando superar dificuldades com seu "esquema de promoção comercial”, desenvolvendo estratégias - que envolviam empresários, exportadores, governos e representações diplomáticas - e realizando detalhados estudos e análises acerca das possibilidades comerciais. A Carteira de Comércio Exterior do Banco do Brasil (Cacex) também teve importante papel, facilitando as liberações das empresas brasileiras interessadas no mercado africano. E também a imprensa, que dava ampla cobertura aos eventos na África, a exemplo da revista

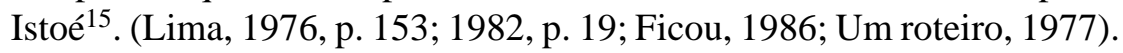

A estrutura financeira demandada pelas relações comerciais teve um importante suporte no Banco do Brasil (com agências em Abidjan, Lagos, Cairo, Casablanca, Dacar, Libreville e Túnis), e no Banco Real (agência em Abidijan) facilitavam a ação das empresas e o financiamento às importações africanas de produtos brasileiros. O Brasil detinha na época $20 \%$ das ações do Biao - Banco Internacional da África Ocidental, com 21 agências na África e cinco na Europa (d'Adesky, 1980, p. 10).

Com a finalidade de facilitar as exportações brasileiras de bens de capital e produtos de consumo duráveis, bem como o pagamento de serviços, foram colocadas linhas de crédito à disposição de países como Angola, Moçambique, Senegal, Costa do Marfim, Gabão, Guiné-Bissau, Níger, Mali e Togo (d’Adesky, 1980, p. 10). O Banco do Brasil colocou em prática linhas de crédito em favor não apenas de suas próprias agências na África, mas também em benefício de entidades financeiras. Essa prática permitia às organizações beneficiárias divulgar, por meio de seus clientes na África, uma lista de produtos que podiam ser importados do 
Brasil, com financiamentos que variavam de cento e oitenta dias a oito anos, com reembolso semestral e a juros prefixados.

A participação do Brasil no Fundo Africano de Desenvolvimento (FAD), com cerca de US\$ 20 milhões - uma das cinco maiores participações no FAD -, contribuiu também para facilitar a participação do empresariado brasileiro nas concorrências e projetos financiados pelo BAD (Banco Africano de Desenvolvimento) ou por ambas as entidades.

\section{O countertrade e outros serviços na relação Brasil-África}

Apesar dessa rede de apoio financeiro, o acesso aos fundos internacionais - indispensável para concretizar a participação brasileira em projetos de envergadura na África - tornava-se cada vez mais difícil. Os fundos recusavamse a conceder empréstimos destinados a projetos brasileiros no Terceiro Mundo (Mourão, 1985, p. 9-10). Uma das soluções utilizadas para contornar a situação foi a introdução da modalidade de troca conhecida como countertrade, que possibilitava o pagamento parcial ou total de mercadorias por meio de mercadorias.

O countertrade constituiu-se em importante instrumento para a facilitação das trocas na África, contornando as barreiras protecionistas do Norte e suprindo a necessidade de divisas decorrente da crise da dívida e da alta dos juros internacionais. De certa maneira, consistia num trunfo de autonomia a ser utilizado nas negociações com os demais países ou organismos internacionais. Para Fonseca (1984. p. 32), executivo da Cotia Trading, dadas as condições dos mercados africanos e brasileiro, a utilização do countertrade revestia-se de um mecanismo de grande significação para o comércio bilateral, considerando-se que

(...) a grande motivação político-econômica que permite justificar as operações de "countertrade" é exatamente em função de utilizar a capacidade ociosa que existe no país em desenvolvimento. E dois motivos básicos justificam a operação: 1) para o "countertrade" se justificar é necessário que existam dois parceiros com escassez de divisas para pagar em moeda não forte; 2) existir bens e serviços excedentes e que encontram demanda potencial no outro (...).

Assim, tendo como base o petróleo, esse sistema foi o principal responsável por um certo deslocamento das compras brasileiras desse produto do Oriente Médio e da América Latina para a África, constituindo instrumento estratégico e fato explicativo para o crescimento avultado do comércio brasileiro com um seleto grupo de países africanos, a exemplo da Nigéria, que na década de 1980 se tornou o maior parceiro comercial do Brasil na África, ensejando inclusive a criação, em São Paulo, da Câmara de Comércio Brasil-Nigéria, em setembro de 1983, e da Câmara de Comércio Nigéria-Brasil, em novembro de 1984, em Lagos, Nigéria. 
As perspectivas sobre o significativo relacionamento entre o Brasil e a Nigéria eram apontadas na época como modelares na cooperação Sul-Sul e exaltadas pelas possibilidades que se abriam de romper a dependência em relação aos países desenvolvidos (Nigéria, 1977). Em visita ao Brasil, em maio de 1977, o ministro das Relações Exteriores da Nigéria afirmava categoricamente que, além do comércio e da transferência de tecnologia, o interesse nigeriano no Brasil dirigiase ao novo tipo de padrão de cooperação que se desenvolvia entre dois países de herança colonial.

A Nigéria foi o primeiro país africano a estabelecer um contrato por countertrade com o Brasil. Por meio dele o Brasil importava cerca de cem mil barris de petróleo por dia e exportava o equivalente a quarenta mil barris diários em veículos, peças e outros produtos, por intermédio da Cotia (a mais importante parceria comercial privada brasileira na Nigéria). Também utilizando o countertrade, a Petrobrás efetuava compras de petróleo junto à estatal Nigerian National Petroleum Company (NNPC) ${ }^{16}$, que recebia em troca o equivalente em serviços, tecnologia e bens de capital, comercializados por meio da Cotia Trading e destinados, em grande parte, à construção de barragens, hidrelétricas, estradas de rodagem, ferrovias, entre outros fins. ${ }^{17}$

Outro acordo importante de countertrade foi estabelecido com Angola, em novembro de 1984, para a construção da hidrelétrica de Capanda, a maior da África, numa empreitada em que a Construtora Norberto Odebrecht se associava a uma empresa soviética fornecedora de turbinas. O custo da construção, previsto inicialmente em US\$ 650 milhões - o maior envolvendo uma construtora brasileira no exterior -, seria parcialmente pago com petróleo angolano, numa base inicial de dez mil barris diários. A Petrobrás também participou de operações de countertrade com Angola, como a associação com a Sonangol, estatal angolana, e com as empresas estrangeiras Petrofina e Bristish Petroleum, para a exploração do petróleo angolano.

Não sendo um meio perfeito nem fácil de fazer negócios, e dada a sua importância, o countertrade mereceu do governo brasileiro uma atenção especial. Criou-se dentro da Cacex uma central de coordenação, o Departamento de Estudos de Mercado (Depem), encarregado de agilizar as operações e identificar novos parceiros potenciais para operações de countertrade.

Um aspecto marcante da aproximação econômica do Brasil com a África no Governo Figueiredo foi a tentativa de criação de uma estrutura própria de comércio envolvendo as mais diversas iniciativas, desde o aperfeiçoamento da estrutura de serviços informativos e informáticos instalada no Departamento de Promoção Comercial do Itamaraty até a criação de trading companies privadas e estatais. Nesse particular, a Interbrás, trading brasileira subsidiária da Petrobrás, estabeleceu associação com 21 companhias instaladas no Brasil e na Nigéria para comercializar cerca de cem produtos industrializados brasileiros sob a marca 
exclusiva Tama. Convém lembrar ainda que a atividade comercial brasileira na África não se restringiu aos países citados anteriormente. Incluiu vários outros parceiros, tais como Moçambique (barcos de pesca e máquinas agrícolas), Zaire (frotas de carros e peças de reposição), além de Tanzânia, Senegal, Mauritânia, Libéria e Costa do Marfim (Estreitamento, 1978).

O comércio de armas foi outro importante segmento nos intercâmbios entre o Brasil e a África na década de 1980. A partir de 1974, quando o Brasil passou a desenvolver capacidade na produção de armas, e particularmente depois de 1977, quando denunciou o acordo de cooperação militar com os Estados Unidos, a indústria bélica adquiriu reputação e espaço para exportar tanques, armas manuais e de artilharia, aviões de treinamento e de guerra (Saraiva, 1996, p. 157). Na África, a Nigéria era a principal compradora de armas brasileiras, além de Gabão, Marrocos, Sudão, Togo, Alto Volta e Zimbábue (Livro, 1991). Por não transparecer nas estatísticas, esse comércio é de difícil percepção, e na época era motivo de certo desconforto para determinados setores empresariais, preocupados com a possibilidade de que ele trouxesse inconvenientes para a exportação de outros bens industriais. A verdade é que a politização do comércio de armas só se comprovou mais tarde (em 1988), a partir da pressão norte-americana contra a venda de um bilhão de dólares em armamentos brasileiros à Líbia.

A transferência de tecnologia e serviços, por sua vez, foi atividade geradora de grandes negócios no continente. Uma das marcas inovadoras do período em questão é uma progressiva abertura dos países africanos à entrada de empresas brasileiras de prestação de serviços, especialmente aquelas voltadas à construção de obras públicas e de infra-estrutura, exploração de petróleo, implantação de projetos agrícolas, realização de estudos de viabilidade de prospecção mineral, mapeamento de solos etc. Inicialmente esses serviços eram executados exclusivamente por companhias estatais brasileiras. As empresas privadas não tardaram a entrar nesse mercado, especialmente as empreiteiras, que marcaram presença no setor. Estas trabalhavam principalmente no regime de joint-venture e, devido à carência estrutural de financiamento local para manterem presença permanente no continente, utilizavam preferencialmente o sistema de built-operatetransfer, que era também muito bem aceito pelos parceiros africanos (Saraiva, 1996, p. 154).

Lafayete do Prado, executivo da Transcon, entende que, pela adequação do estágio tecnológico brasileiro à necessidade dos países do Terceiro Mundo, o Brasil estaria preparado para vender diversos tipos de serviços a esses países. “As áreas vedadas à presença brasileira, por carência de maturidade tecnológica, dificilmente se inserem na demanda daqueles países. Além disso, em vários, setores como o de transportes, hidrelétricas e indústrias básicas, a nossa maior afinidade com os níveis atuais dos países potencialmente recipientes conta a nosso favor.” Ele acrescenta ainda que, diante disso, as relações comerciais brasileiras eram 
priorizadas pelos africanos em razão de fatores como "necessidade reconhecida de apoio e a disposição favorável do Brasil para isso, falta de periculosidade de ingerência nos assuntos internos desses países, e, quanto à maior parte das nações africanas, somos hipóteses alternativas em face dos antigos colonizadores” (Brasil, 1981, p. 6).

A esse respeito, as empresas prestadoras de serviços de engenharia destacaram-se em termos da dimensão da transferência de tecnologia, bem como pelo volume de divisas envolvido nas negociações. De certo modo, a crise do mercado interno brasileiro de construção civil contribuiu para a maior presença dessas empresas no mercado externo. Entre estas, podemos citar a Mendes Júnior, pioneira nesse campo com a construção da Transmauritânia, que atuou principalmente na construção de estradas e aeroportos na Nigéria e na Mauritânia; a Norberto Odebrecht, que desenvolveu projetos de construção de estradas, hidroelétricas e hotéis em Angola, envolvendo-se no setor de óleos por meio de sua subsidiária Tenenge; a Ecisa, que construiu a rodovia Morogaro-Dodoma, na Tanzânia; a Andrade Gutierrez, que utilizou o sistema built-operate-transfer para contratos de construção e gerenciamento de minas de ouro no Zaire, além de construir estradas nos Camarões e no Congo, onde foi responsável, em 1984, por uma rodovia de $134 \mathrm{~km}$ em plena floresta equatorial, envolvendo cerca de dois mil trabalhadores, dos quais quinhentos brasileiros; a Sisal, que preparava pessoal e reformava hotéis para tornar a capital angolana viável a estrangeiros.

Foram muitas as companhias que tiveram seus nomes ligados ao desenvolvimento das relações econômicas do Brasil com o continente africano. Entre elas, ainda podemos citar a Pão de Açúcar, uma das primeiras empresas privadas a estar presente no continente; a Hidroservice, que desenvolveu importantes trabalhos de consultoria para implantar serviços de comunicação junto à Companhia de Comunicação da Nigéria, em Lagos, chegando a recrutar cerca de trinta engenheiros em São Paulo, e participando ainda da produção de aço em Abeokuta; a Sobratel, a Protec e a Promon, na área de serviços de comunicação. Esta última chegou a levar cento e quarenta engenheiros brasileiros para atuarem na Nigéria (Infra-estrutura, 1977).

O fornecimento de "pacotes" de engenharia foi uma estratégia bastante utilizada pelas empresas brasileiras de serviços para compensar sua falta de competitividade no continente africano. Conforme revela Roberto Prisco Ramos, executivo da Montreal Engenharia, faltavam ao Brasil condições

(...) para concorrer com as empresas da Coréia e com as que empregam mão-deobra indiana e paquistanesa - muito mais barata. Mas conseguimos equilibrar e até levar vantagem dentro das operações chamadas "pacote" (package deal), onde colocávamos bens de equipamentos nacionais, pois aqueles países não tinham o parque industrial que nós possuíamos (...) (Empresas, 1981, p. 35) ${ }^{18}$. 
O volume de serviços prestados nessas condições assumiu proporções consideráveis, acarretando para o Brasil as óbvias vantagens que esse tipo de exportação traz (Calcagnoto, 1985, p. 78). Como reconhece a Fiesp: “(...) para cada dólar de serviços exportados, iam três de manufaturados. Rodovias, ferrovias, hidrelétricas, cadeias de hotéis são alguns dentre os muitos exemplos arrolados para documentar o contributo brasileiro à modernização de países africanos (...)”.

Outra estratégia muito utilizada para gerar exportações consistiu na concessão de empréstimos condicionados à aquisição de bens manufaturados brasileiros, como é o caso das operações efetuadas com o Senegal e o Gabão em 1974, pelas quais o Brasil emprestava a esses países em contrapartida à compra de produtos brasileiros (Brasil, 1974). A utilização dessa e de outras estratégias possibilitou o extraordinário crescimento do comércio Brasil-África nesse período.

\section{Dificuldades e declínio das relações Brasil-África}

Muitos obstáculos se fizeram presentes nesse relacionamento, alguns dos quais contribuíram decisivamente para o declínio gradativo da importância do comércio do Brasil com a África ao longo da segunda metade dos anos 1980 e, mais incisivamente, nos anos 1990. Trata-se de obstáculos que, conforme Pimentel (2000, p. 9), podem ser distinguidos como genéricos - enfrentados por empresas de qualquer país, instaladas ou em operação na África - ou específicos das empresas brasileiras.

Os primeiros estariam vinculados à situação de instabilidade política e econômica da maioria dos países africanos, desencorajando investimentos e gerando um "custo África” que fez diminuir o interesse pelo continente. As dificuldades específicas do empresariado brasileiro estariam vinculadas ao desconhecimento mútuo e à preferência africana pelas empresas européias e seus produtos, em razão dos sólidos vínculos comerciais com as ex-metrópoles. Além disso, também influíram a insuficiência de transportes diretos; a utilização de práticas indevidas, como protecionismo, subsídios e reserva de mercados em prejuízo das empresas brasileiras; a deficiência dos mecanismos de crédito e seguros das exportações brasileiras; as similaridades de produtos etc. Vale ressaltar que, antes da visita do ministro Gibson Barbosa à África em 1973, a revista Conjuntura Econômica (1973, p. 90) já apontava alguns desses obstáculos.

Os empresários brasileiros enfrentaram algumas dificuldades para as quais não estavam preparados, tais como a diversidade de culturas e os desníveis de desenvolvimento de país para país, bem como as diversas línguas dos interlocutores. Alguns executivos brasileiros que atuaram no continente africano registraram os problemas enfrentados. O empresário Freddy Aflalo alertava que, para o brasileiro se instalar na África, era necessário primeiro saber com quem lidar. O único método para isso, segundo ele, era “a avaliação objetiva do mercado, dos homens 
e das sociedades africanas”. Advertia também que o primeiro passo consistia em "despir-se dos preconceitos, do racismo intrínseco que povoa a mente dos nossos executivos, que leva a uma atitude paternalista ou, o que é pior, de antagonismo" (Saiba, 1981, p. 32).

Boaventura d'Avila Filho, executivo da Tecnometal, empresa que realizou estudos sobre a indústria no Congo e no Gabão, salientava que soluções brasileiras, como o emprego de mão-de-obra local em larga escala, eram muito mais consentâneas com a realidade africana do que um modelo de fábrica robotizada norte-americana ou japonesa. Ele ponderava, no entanto, que uma das maiores dificuldades era o quase completo desconhecimento, por parte dos brasileiros, da realidade histórica, política e étnica dos países africanos, o que o levara, para bem executar o seu trabalho, a contratar um especialista (Nova, 1983, p. 14).

Outra dificuldade, segundo Oliveira (1987, p. 151), advinha do fato de os levantamentos de dados (econômicos, demográficos, comerciais e outros) sobre a maioria dos países africanos serem adquiridos na Europa, o que implicava informações desatualizadas ou distorcidas da realidade africana. As dificuldades apontadas por esses empresários e estudiosos, somadas à crise econômica mundial do início dos anos 1980, reduziram a capacidade do Brasil em dar sustentação à política comercial relativa ao mercado africano. Assim, no Governo Sarney (198590), o comércio brasileiro começou a declinar. Seus índices retornaram a valores semelhantes àqueles dos primórdios do intercâmbio, com uma participação entre 3,5 e $4 \%$ do total das exportações brasileiras para todo o mundo ${ }^{19}$. Os anos 1990 trouxeram, além de mudanças no mundo como um todo, a consolidação políticoinstitucional, o redimensionamento do Estado e a abertura econômica. Voltou-se a privilegiar as relações com os Estados Unidos e a Europa, ao mesmo tempo em que se incrementaram as relações com a Ásia. O sucesso do Mercosul fez as atenções do empresariado convergirem para os vizinhos do continente, fazendo com que a África perdesse os atrativos que nos anos 1970 levaram ao brilho e à ousadia da política africana daquele período.

A tendência de baixa nesse comércio não significa, contudo, o fim do intercâmbio, pois a política persiste, embora de maneira seletiva, com prioridades precisas e bem delimitadas no continente. A política africana dos anos 1970 e parte dos anos 1980 cede lugar a um enfoque recortado a poucos países, regiões e temas. Os interesses se voltam para a África Austral, nomeadamente a África do Sul, um dos raros países ao sul do Saara que têm conseguido superar as crises de desenvolvimento por que passa o continente africano, registrando níveis históricos de crescimento. Seus níveis de intercâmbio com o Brasil elevaram-se substancialmente em relação às décadas anteriores, alcançando, de 1992 a 1994, entre US\$ 350 milhões e US\$ 400 milhões (Banco do Brasil, 1995).

Em discurso realizado na celebração do Dia da África, em 25 de maio de 1995, o ministro das Relações Exteriores reconhece na África uma das grandes 
oportunidades que se abrem para o Brasil, listando razões que estimulariam essas relações, tais como: a) a proximidade relativa entre o Brasil e a África e o fato de que grande parte do continente compartilha conosco o Atlântico, uma base física que também facilitou as relações comerciais no passado; b) a condição de país em desenvolvimento que, em diferentes gradações, o Brasil compartilha com a totalidade do continente africano; c) a complementaridade existente entre a economia brasileira e as economias africanas, que era forte no passado e deveria ser reavaliada no presente; d) a importância da África como parceira internacional, com cinqüenta países, diversas culturas e muitas interfaces geográficas - com o Mediterrâneo, o Oriente Médio, a península Ibérica, o Atlântico Sul e o oceano Índico; juntamente com um peso político próprio, a extensa e variada África, mesmo enfrentando problemas, oferece janelas de oportunidades para parcerias com países em desenvolvimento; e) a grande semelhança de condições físicas, climáticas e sociais entre o Brasil e muitos países africanos, gerando uma importante "identidade regional” em termos de desenvolvimento tecnológico e adaptabilidade de técnicas para os vários tipos de ambientes tropicais que o Brasil compartilha com seus parceiros africanos (Lampréia, 1995, p. 205).

Além disso, os novos rumos da realidade internacional incentivam a cooperação de empresas e governos, abrindo espaços para a expansão de associações entre países com objetivos afins. Diante disso, importantes vias de expansão desse comércio prenunciam estabelecer-se a partir dos espaços que se consolidam com a criação das ZPCAs e da Comunidade de Países de Língua Portuguesa (CPLP).

\section{Perspectivas empresariais: considerações finais}

Ao voltar a atenção para as relações econômicas Brasil-África, observamos tratar-se de um intercâmbio de há muito estabelecido, mas que, no cômputo geral, ganhou relevância no período compreendido entre os anos 1970 e 1990, ocasionando uma grande movimentação do empresariado brasileiro em direção ao mercado africano.

Como pudemos observar, essa movimentação foi conduzida no âmbito da estratégia governamental de substituição de importações, tratando-se, mais especificamente, de um desdobramento dessa estratégia, ou seja: à medida que o crescimento da indústria nacional via substituição de importações gerava estoques invendáveis, a busca de compradores no exterior fazia-se necessária para o escoamento da produção excedente. Essa necessidade tornou-se premente com o acirramento das tendências protecionistas dos países industrializados e a vulnerabilidade externa da economia brasileira no período. Com isso, o governo se viu forçado a incentivar não apenas as exportações de artigos de maior valor agregado (manufaturados), mas também a conquista de novos mercados. 
Sob o estímulo das emergentes relações Sul-Sul, que incentivavam o intercâmbio entre países do Terceiro Mundo, a busca por novos mercados vai encontrar na África uma importante opção para o destino das exportações de manufaturados brasileiros. Essa opção era favorecida não apenas pela destacada fonte de suprimento de petróleo e outras matérias-primas cruciais ao desenvolvimento do modelo econômico implantado no Brasil em que se constituíam os países africanos, mas igualmente pela manifesta disposição destes em encontrar parceiros no contexto Sul-Sul.

Nesse quadro, no início dos anos 1970, o governo concedeu forte estímulo a multinacionais estrangeiras com filiais no Brasil e empresas de capital nacional para direcionarem parte de suas exportações para o continente africano. Sob o impulso do Itamaraty e de outros órgãos de governo, o Estado investiu maciçamente na conquista de novos mercados na África, viabilizando empreendimentos que de outra forma enfrentariam pesados obstáculos, especialmente em razão da falta de liquidez das nações africanas e das dificuldades de obtenção de moeda forte junto a bancos e entidades internacionais.

Estreitaram-se laços políticos, criaram-se embaixadas, promoveram-se eventos diversos, estimulando-se também o desenvolvimento de novos meios e formas de facilitar as exportações para o continente africano. Apostava-se nas potencialidades da região, ao tempo em que se buscava persuadir setores influentes da sociedade para se engajarem no esforço exportador do governo. Isso pode ser percebido pelo grande número de eventos patrocinados pelo governo brasileiro nesse período, além das facilidades e incentivos (fiscais, creditícios, cambiais, entre outros) concedidos aos empreendimentos que exportavam para a África.

As atividades de fomento à exportação fizeram com que diversas empresas surgissem nesse período ou voltassem seus empreendimentos para o mercado africano, contribuindo, dessa forma, para que a participação africana no total do comércio exterior brasileiro, ao início dos anos 1980, se elevasse a índices jamais alcançados. Essa situação chama a atenção na medida em que o auge dessas relações foi alcançado num período, do ponto de vista econômico, bastante conturbado para o Brasil - a década de 1980 foi considerada uma “década perdida”, de grave desequilíbrio nas contas externas e de inflação alta, quase incontrolável.

Nos anos 1990, o intercâmbio comercial regrediu. A crise econômica que abalou o mundo ao final dos anos 1980 atingiu profundamente as economias africanas, retirando-lhes a capacidade de ampliar suas relações com o Hemisfério Sul. O Brasil, por sua vez, ao efetuar a renegociação da dívida externa, perdeu parte de sua liquidez e conseqüentemente grande parcela de sua capacidade de sustentar uma política em direção à África, concedendo subsídios, incentivos e demais facilidades às exportações.

A política de estabilização da economia e a reforma do Estado brasileiro exerceram consideráveis influências no arrefecimento desse comércio, na proporção 
em que levaram o País a eleger uma política cuja abertura comercial privilegiava a relação com os tradicionais parceiros industrializados (Estados Unidos e União Européia) e priorizava uma política regional em direção ao Mercosul. Isso tornase evidente nas palavras do ministro das Relações Exteriores do Brasil, em 1995, ao afirmar que uma prioridade da política externa brasileira "é o processo de consolidação do Mercosul, o seu eventual engrandecimento com a incorporação de novos parceiros, o seu relacionamento com outras comunidades econômicas, com destaque para a União Européia e Nafta e sua incidência na estabilização e na retomada do crescimento" (Lampréia, 1975, p. 115). Com a reforma do Estado, percebe-se que, do ponto de vista do comércio externo, o País se distancia da África. Conformando-se com os princípios da globalização e do livre mercado, que estimulavam a desregulamentação e a privatização, o papel do Estado vai progressivamente diminuindo.

Como se pôde inferir, a reaproximação do Brasil com a África nos anos 1970 não foi um fato natural, decorrente dos anos de contatos com o continente africano, mas um ato político decorrente de um projeto de inserção internacional para o Brasil que buscava na África atender interesses materiais e políticos de afirmação de autonomia no mundo.

Contudo, não se pode desprezar a disposição do empresariado brasileiro em aproveitar as oportunidades de negócios surgidas no âmbito do comércio BrasilÁfrica, como também o seu empenho no enfrentamento de dificuldades nada convencionais. Aí estariam incluídos o conflito angolano, a preferência africana por produtos e serviços europeus, a insuficiência de transportes diretos e o desconhecimento mútuo das respectivas realidades.

Tais competências desenvolvidas ao longo dos anos fazem com que alguns desses empreendimentos ainda hoje prossigam atuando em operações voltadas para o comércio africano, a exemplo da Câmara de Comércio Brasil-África e a Construtora Norberto Odebrecht.

No caso da Câmara percebeu-se que, em face de uma insuficiente conformação aos novos ditames do mundo dos negócios, suas atividades se reduziram, evidenciando a perda de uma parcela de sua força negocial. Por sua vez, os novos cenários do mundo dos negócios exigem a utilização intensiva de modernas ferramentas de gestão. Estas parecem incorporar-se de forma bastante lenta ao dia-a-dia da Câmara de Comércio Afro-Brasileira, que não possui uma página na web e parece utilizar pouco a internet, além de possuir um banco de dados que carece de atualização. Tais constatações estariam a indicar a necessidade de sérias reformulações na forma de atuação da Câmara a fim de que esta possa continuar a exercer o significativo papel desempenhado nos "anos de ouro” do comércio Brasil-África. Seu nome, sua história e seu passado constituem um legado que não se pode desprezar, tendo em vista a ampla experiência 
e o grande conhecimento acumulados ao longo dos anos no desenvolvimento de negócios no continente africano.

No que tange à atuação da Odebrecht em Angola, pudemos perceber que se tratou de uma experiência muito bem sucedida, cujos resultados positivos permitiram a essa empresa firmar-se na atualidade como uma das mais importantes forças da construção civil naquele país, executando grandes obras de engenharia, diversificando seus negócios e instalando subsidiárias. Diversos fatores contribuíram para o êxito dessa empresa em território angolano. Além do forte apoio governamental, identificamos o bom relacionamento entre os dois países, a língua comum, a planejada integração e parceria no mercado local, o investimento na capacitação tecnológica e gerencial das equipes, a aplicação de modernas formas de gestão e uma desenvolvida capacidade de mobilizar pessoas, recursos estratégicos, financeiros e políticos, com vistas a atingir seus objetivos.

A despeito das mudanças no ambiente econômico brasileiro e da redução progressiva do apoio estatal nos anos 1990, a Odebrecht experimenta uma continuada ampliação de suas atividades no continente africano. Ela se instalou em outros países da região e, por meio do "efeito vitrine", ampliou o seu raio de ação para outros continentes. Por tais constatações, a experiência da Odebrecht estaria a demonstrar que as relações comerciais com o continente africano são viáveis, suscitando diversas indagações: será que hoje em dia uma grande empresa brasileira que desejasse iniciar negócios na África poderia conseguir êxito seguindo o modelo adotado pela Odebrecht? E no caso de uma pequena ou média empresa?

Diante do que apresentamos ao longo deste texto, percebe-se que as condições no Brasil se modificaram e, portanto, uma empresa brasileira que, resolva iniciar operações dirigidas ao mercado africano terá de partir de novas bases, já que não poderá contar com a vasta gama de incentivos creditícios e financeiros concedidos no passado pelo governo brasileiro. Extinguiram-se as linhas diretas semanais que ligavam o Brasil a diversas cidades africanas, como Lagos (Nigéria), Abidjan (Costa do Marfim), Luanda (Angola) e Maputo (Moçambique). À exceção dos dois vôos diretos semanais para a África do Sul, os contatos aéreos com o continente africano se efetuam de forma triangular, com passagem pela Europa.

Com o capital financeiro escasso no Brasil e nos países africanos, em lugar dos empréstimos a juros subsidiados, antes concedidos por bancos oficiais, as empresas são hoje obrigadas a contar com seus próprios recursos ou recorrer a empréstimos a taxas de juros de mercado oferecidos pelos bancos privados. Em contrapartida, no horizonte do século XXI, o Brasil, da mesma forma que os países africanos, ampliou o conhecimento sobre esse intercâmbio. Cresceu no País o número de centros de estudos sobre a África, contabilizando um reforço em termos de capital intelectual e de recursos humanos proveniente do maior número de africanos e brasileiros que atuaram nesse comércio. 
A rede mundial de computadores facilitou o conhecimento de oportunidades de negócios. Análises de possibilidades de países e mercados africanos podem ser inferidas de sites de organismos internacionais, como os da ONU, Onudi, OUA e FAO, entre outros. A BrazilTradeNet (www.braziltradenet.gov.br), site do Departamento de Promoção Comercial do Ministério das Relações Exteriores, oferece gratuitamente um amplo conjunto de oportunidades de negócios, informações e pesquisas sobre produtos e mercados, endereços úteis, notícias, links e outros dados de interesse para exportadores brasileiros. Nesse site, a empresa pode incluir uma oferta de exportação para ser consultada por congêneres de fora do Brasil, além de obter informações sobre as condições gerais de acesso de seu produto a um país ou bloco econômico. Assim, uma pequena ou média empresa que esteja procurando negócios no mercado africano deve incorporar a internet à sua rotina de trabalho. A isso se deve acrescentar a busca de oportunidades junto a câmaras de comércio ${ }^{20}$, consulados e embaixadas de países africanos no Brasil.

Já no caso de uma grande empresa, a especialização e o aprimoramento dos recursos humanos e tecnológicos revestem-se de importância capital. Dispondo de departamento de exportação próprio, a permanente atualização de seus quadros, em sintonia com as tendências mundiais, a torna mais capacitada para atuar nesses mercados. A assinatura de periódicos especializados em África, o envio de representantes para conhecer pessoalmente as potencialidades dos países africanos, o permanente contato com empresas estrangeiras e nacionais que detêm o conhecimento dos mercados locais constituirão importantes ferramentas a serem consideradas. Em certas circunstâncias, seria recomendável buscar a associação com outras empresas em torno de projetos de joint-venture. Convém ainda ressaltar que, a exemplo das grandes empresas européias, norte-americanas e asiáticas, a intenção de permanecer no continente africano parece fator de grande importância para o sucesso nesse tipo de empreendimento, haja vista que essa presença contínua tende a propiciar um maior domínio dos mecanismos comerciais, assim como maior rapidez na adaptação aos mercados.

Caberia acrescentar que as considerações aqui apresentadas advêm do entendimento de que as conjunturas brasileira, africana e internacional estão continuamente a criar novas oportunidades e desafios que não podem ser ignorados pelos homens de negócios deste País, a despeito das dificuldades que sempre existirão nas relações com qualquer país ou região. No caso africano, tais dificuldades estariam vinculadas sobretudo à recorrente instabilidade política e econômica de boa parte desses países, determinando um “custo África” que cria obstáculos à instalação ou operação de empresas brasileiras naquele continente.

Buscando averiguar quais os mercados africanos que se apresentariam como promissores para o desenvolvimento de negócios brasileiros nos horizontes do ano 2002, o pesquisador consultou Especialistas em África e deles recolheu 
impressões que nos levaram à conclusão de que, excluídas algumas grandes empresas que procuraram consolidar sua presença no continente, o setor privado brasileiro não está familiarizado com as diferenças entre os diversos países africanos. Por isso, tende a julgar a África como um todo em função dos aspectos negativos ressaltados pela imprensa, da mesma forma que, em sentido inverso, muitos empresários africanos desconhecem a qualidade de nossos produtos e serviços.

Percebeu-se ainda que as relações comerciais entre o Brasil e o continente africano hoje se concentram, em grande medida, nos países petrolíferos, como Líbia, Nigéria, Gabão, Argélia, Angola e Congo Brazzaville. Além desses países, destaca-se a África do Sul, que desponta como parceiro de elevado valor estratégico em função de sua posição geográfica e do seu nível de desenvolvimento industrial, que é elevado em comparação com os de outros países africanos. Brasil e África do Sul são os pólos mais desenvolvidos do capitalismo em seus respectivos continentes, o que se expressa não só na grandeza de seus PIBs, mas também nos respectivos graus de sofisticação industrial. Acrescente-se a isso a condição privilegiada de observador de que a África do Sul desfruta no Mercosul, além do fato de poder ser considerada um trampolim para a penetração em todo o subcontinente da África Austral, região de apreciável valor econômico derivado da produção e reserva de vários minerais estratégicos, situada entre os oceanos Índico e Atlântico e fronteiriça ao cone sul da América Latina.

Também o mercado dos países africanos da CPLP foi apontado como um mercado potencial para a venda de mercadorias e serviços, tais como a construção civil, a agropecuária, etc. A língua portuguesa comum e o interesse político do governo brasileiro em desenvolver maior cooperação representariam um grande atrativo para impulsionar um intercâmbio comercial de grandes potencialidades. Trata-se de um mercado com cerca de quarenta milhões de pessoas cujas afinidades culturais e familiaridade com o Brasil são estimuladas por condições semelhantes em termos de terreno e de clima. Além disso, as empresas brasileiras possuem vantagens comparativas para participar no desenvolvimento africano, pois o patamar tecnológico dessas empresas permite a atuação em setores de média complexidade, dotados de capacidade indutora, como a formação profissional, a construção civil, a agricultura e outros.

Trata-se de perspectivas múltiplas e atraentes, que ainda assim nos apontam para novas questões: sob que outras formas de atuação empresas brasileiras se estabeleceram no continente africano no período estudado? Que situações poderiam ser apontadas como potencializadoras do sucesso (ou do fracasso) dessas iniciativas? Em tempos de globalização, com o peso hegemônico das relações econômicas Norte-Sul, seria possível ou desejável reativar o intercâmbio Sul-Sul? Será que, no contexto da globalização, o governo brasileiro deveria voltar a priorizar as relações com a África? São questões, como muitas outras, cujas respostas 
seriam de muita utilidade para pesquisadores interessados no tema das relações comerciais Brasil-África, além de ampliar o conhecimento sobre o comportamento do empresariado nacional, provendo o campo da administração (fortemente contaminado por influências estrangeiras) com informações retiradas do contexto brasileiro - rica fonte de ensinamentos para as novas gerações de empreendedores.

Agosto de 2003

\section{Notas}

1 Este artigo resultou de dissertação de mestrado em Administração e Comércio Internacional. Agradeço os comentários e orientações do Dr. Jacques D’Adesky e da Dra. Climene Laura de Camargo.

2 O desenvolvimento da pesquisa ressaltou a quase inexistência de estudos sobre negócios brasileiros a partir da realidade nacional, justificando as ponderações de Aquino (1986) quanto ao estudo da administração em nosso país ser fortemente contaminado por influências estrangeiras fazendo com que um vasto número de experiências empresariais e de gestão sejam pouco exploradas, o que poderia fornecer substanciais contribuições ao campo da administração, provendo instituições responsáveis pela formação de novas gerações de empreendedores de informações retiradas do próprio contexto nacional.

3 A Cepal era uma organização latino-americana voltada para a proposição de políticas e para a assessoria. Seus estudos concentravam-se em políticas capazes de viabilizar o processo de industrialização, buscando superar os obstáculos ao desenvolvimento (Santos, 2000, p. 81). Tais produtos passaram a ser objeto de barreiras tarifárias e não-tarifárias, e portanto foram os primeiros a ser substituídos pela produção local.

5 Vale ressaltar que essa pauta de importações, quando analisada do ponto de vista de categorias de uso, delineava, ao final dos anos 1980, o perfil de uma economia industrializada.

6 A situação agrava-se no início dos anos 1970 com a perda da Guerra do Vietnã pelos Estados Unidos e o conseqüente déficit no Tesouro americano. Esse fator, conjugado com o fim do padrão ouro do dólar e a elevação dos preços do petróleo, provocou uma recessão ainda maior nos países industrializados.

7 Grupo formado por países em desenvolvimento que buscavam uma linha de independência política no conflito Leste-Oeste.

8 Foi o caso, em 1975, do reconhecimento do governo angolano, atitude que custaria ao Brasil uma reprimenda do governo americano e a recriminação de setores do regime militar brasileiro. Em contrapartida, foi a garantia de portas abertas para empreendimentos brasileiros que até hoje se encontram ativos, a exemplo da Construtura Norberto Odebrecht (Saraiva, 1999).

9 Boa parte da atração exercida pelos mercados africanos pode ser explicada pela elevada dependência brasileira em relação à importação de petróleo, cujo suprimento era imprescindível à manutenção do ritmo industrial brasileiro, e que foi um dos itens mais significativos da política comercial para a África.

10 Ver no Anexo 10, listagem de importantes vendas de serviços na África, no período mencionado.

11 Esses eventos, em grande parte, realizavam-se sob a chancela do Itamaraty, e consistiam na organização de missões e feiras comerciais, na realização de seminários, na divulgação de oportunidades por meio de embaixadas e outras agências governamentais no exterior, e assim por diante.

12 General Agreement on Tariffs and Trade - Acordo Geral sobre Tarifas e Comércio. 
13 O setor industrial foi especialmente afetado, com a sua produção ficando em 1992 abaixo do nível atingido em 1980.

14 A diretriz básica do programa Befiex era vincular um comprometimento de exportação à importação de maquinário com a renúncia da carga de impostos. Empresas inseridas no Befiex tinham direito de saldar o comprometimento de exportação num período de até dez anos.

15 Até 1974, o Brasil contava com apenas 12 embaixadas residentes na África. Em 1984 esse número sobe para 21. As relações diplomáticas do Brasil no final do Governo Figueiredo passaram a abranger 43 das 52 nações africanas.

16 “Countertrade paga até 80\% do petróleo”. Gazeta Mercantil, de 09.09.85. Esse contrato da Petrobrás com a NNPC - um dos maiores contratos da indústria petrolífera ocidental - não foi renovado em janeiro de 1986. Segundo PEREIRA (1985, p. 102), os exportadores brasileiros foram acusados de superfaturamento nas mercadorias exportadas, com a cumplicidade de autoridades nigerianas: uma grande soma em dólares teria sido comprometida a título de pagamento de comissões pelo fechamento do acordo.

17 A Cotia Trading, notabilizou-se pelo estabelecimento de joint-ventures locais, como a Leman Industries (metalurgia), a Lemarco Entreprises (construção civil, transportes, armazenagem), a Projex West Africa (projetos agropecuários, assistência técnica agrícola), a Lemaco Ltd. (granja avícola integrada, abatedouro), a Drinco Industries (refrigerantes) e a Nigeria Ranches (fazendas de gado, frigoríficos).

18 Esse artigo traz ainda a opinião de representantes de três das maiores firmas exportadoras brasileiras do setor de construção: Mendes Junior, Ecisa e Montreal.

19 Em 1990, as exportações do Brasil para a África chegaram a alcançar US\$ 1 bilhão, ficando em torno de 3\% do total das exportações brasileiras para todo o mundo.

20 As câmaras voltadas para o comércio africano são: Câmara de Comércio Afro-Brasileira, Brasil-Angola, Brasil-República Sul-Africana e Brasil-Nigéria.

\section{Bibliografia}

ALMEIDA, P. R. de. Relações internacionais e política externa do Brasil: do descobrimento à globalização. Porto Alegre: UFRGS, 1998.

ALVES D. O. A.; SAYAD, J. O plano estratégico de desenvolvimento 1968-1970. In: LAFER B. M. (Org.). Planejamento no Brasil. São Paulo: Perspectiva, 1987, p. 91.

BANCO DO BRASIL, Annual Report. Rio de Janeiro, 1982/1995, p. 30.

BRASIL pode aumentar exportação de serviços. Informativo CE, Rio de Janeiro, n. 46, set. 1981, p. 6.

BRASIL. Ministério das Relações Exteriores. Resenha de Política Externa do Brasil, Brasília, n. $1 / 2,1974$

CALCAGNOTO G. O relacionamento econômico Brasil-África: corda bamba entre cooperação econômica e a nova dependência Sul-Sul. Estudos Afro-Asiáticos, Rio de Janeiro, n. 11, p. 71-81, 1985.

CONJUNTURA ECONÔMICA. Brasil e os mercados da África. Rio de Janeiro: FGV, v. 27, n. 4, abr. 1973.

COUNTERTRADE paga até 80\% do petróleo. Gazeta Mercantil, São Paulo, 09 set. 1985.

CUNHA, S. H. P. As relações Brasil-Angola 1975-1980: um estudo de caso sobre as relações SulSul. Salvador, 1991. Dissertação (Mestrado em Economia) - Eeco, UFBA.

D’ADESKY, J. As relações econômicas Brasil-África no contexto das relações internacionais. Estudos Afro-Asiáticos, Rio de Janeiro, n. 11, p. 63-70, 1985.

D’ADESKY, J. Brasil-África: convergência para uma cooperação privilegiada. Estudos AfroAsiáticos, Rio de Janeiro, n. 4, p. 5-19, 1980. 
D’ADESKY, J. Intercâmbio comercial Brasil-África 1958-1977: problemas e perspectivas. Estudos Afro-Asiáticos, Rio de Janeiro, n. 3, p. 5-34, 1980.

EMPRESAS brasileiras executam obras e projetos em 34 países. Jornal do Brasil, Rio de Janeiro, p. 35, 26 jul. 81.

O ESTREITAMENTO de relações com a África Ocidental. Gazeta Mercantil, São Paulo, 24 dez. 1978

FICOU fácil ir até a Nigéria. Isto É, São Paulo, 28 set. 1986.

FONSECA, R. G. da. A experiência profissional nas novas formas de comércio. In: SEMINÁRIO COUNTERTRADE E OUTRAS ALTERNATIVAS COMERCIAIS E FINANCEIRAS NA EXPORTAÇÃO, São Paulo: Fundação Centro de Estudos do Comércio Exterior, 1984.

FRAGOSO, J. L. R. Notas sobre a política externa brasileira dos anos 50-70. Estudos AfroAsiáticos, Rio de Janeiro, n. 10, p. 5-29, jun. 1984.

INFRAESTRUTURA atrai empresas. Jornal do Brasil, Rio de Janeiro, 22 jul. 1977.

LAFER C. O Brasil e a crise mundial. São Paulo: Perspectiva, 1984.

LAMPRÉIA, L. F. Apresentação na Comissão de Relações Exteriores da Câmara dos Deputados Resenha de Política Exterior do Brasil, Brasília, n. 76, p. 113, 1975.

LIMA, P. T. F. de. Diplomacia e comércio: teoria e prática. Revista Brasileira de Estudos Políticos, Belo Horizonte, v. 42, p. 153-173, 1976.

LIMA, P. T. F. de. Comércio exterior do Brasil: participação do Itamaraty no processo de promoção das exportações. Revista Brasileira de Estudos Políticos, Belo Horizonte, n. 54, p. 19-37, 1982.

LIVRO revela segredos da indústria bélica: setor é dominado por Itamaraty e militares. Jornal do Brasil, Rio de Janeiro, p.14, 9 jun. 1991.

MOURÃO, Fernando A. A. A cooperação internacional e as relações internacionais. In: ENCONTRO ANUAL DA ANPOCS, 9., 1985, São Paulo. Anais... São Paulo, 1985. p. 9-10

NIGÉRIA à espera de mais carga. Gazeta Mercantil, São Paulo, 19-21 nov. 1977.

NIGÉRIA quer investimentos brasileiros. Folha de São Paulo, São Paulo, 26 maio 1977.

NIGÉRIA quer Terceiro Mundo independente. O Globo, Rio de Janeiro, 26 maio 1977.

NOVA técnica abre mercados em países africanos. Comércio Exterior, São Paulo, n. 70, p. 14, jan. 1983.

OGWU, U. J. Cooperação Sul-Sul: problemas, possibilidades e perspectivas de uma relação emergente. Estudos Afro-Asiáticos, Rio de Janeiro, n. 10, p. 9-19, 1985.

OLIVEIRA, H. A. de. Política externa brasileira e relações comerciais Brasil-África. São Paulo, 1987. 167 f. Tese (Doutorado em Ciências Sociais), Faculdade de Filosofia Letras e Ciências Humanas, Universidade de São Paulo.

PEREIRA, J. M. N. Brasil-África no governo Figueiredo: um balanço. Contexto Internacional , Rio de Janeiro, n. 2, p. 81-104, 1985.

PERONA, N. B. Os convênios de Lomé e sua influência no comércio entre a América Latina e África. Estudos Afro-Asiáticos, Rio de Janeiro, n. 11, 1985.

PIMENTEL J. V. de S. Relações entre o Brasil e a África subsaárica. Revista Brasileira de Política Internacional, Rio de Janeiro, n. 43, p. 5-23, 2000.

PINHEIRO A. C. e MOREIRA, M. M., Investimentos e comércio Brasil-África do Sul: presente e futuro. In: GUIMARÃES, S. P. (Org.). Brasil e África do Sul: riscos e oportunidades no tumulto da globalização. Brasília: CNPq, p. 333, 1997.

SAIBA como negociar com os africanos. Senhor, São Paulo, n. 34, p. 32, jan. 1981.

SANTOS, T. A teoria da dependência: balanço e perspectivas. Rio de Janeiro: Civilização Brasileira, 2000.

SARAIVA. J. F. S. O lugar da África: a dimensão atlântica da política externa brasileira de 1946 a nossos dias. Brasília: UnB, 1996. 
SARAIVA. J. F. S. Olhares Atlânticos - África e Brasil no mundo contemporâneo. Humanidades, Brasília, n. 47, p. 6-20, 1999.

SARDENBERG, R. M. A evolução da política externa do Brasil nas duas últimas décadas. Brasília, jun. 1980, 27 p. Documento mimeografado.

SELCHER W. Dilemas políticos na relações Brasil-África: obstáculos políticos nas relações SulSul. Estudos Afro-Asiáticos, Rio de Janeiro, n. 10, p. 55-72, jun. 1984.

UM ROTEIRO para o investidor. Isto É, São Paulo, 14 dez. 1977.

\section{Resumo}

Este artigo traz algumas reflexões acerca da presença empresarial brasileira no mercado africano, enfocando particularmente a visão de diferentes autores que se voltaram para o estudo das relações comerciais entre o Brasil e a África. $\mathrm{O}$ texto objetiva responder a duas questões principais. Primeiramente, sob que motivações o comércio Brasil-África obteve um notável crescimento entre os anos 1970 e 1990? Segundo, quais as perspectivas que se apresentam para o empresário brasileiro que deseje iniciar negócios na África? Através da pesquisa bibliográfica e entrevistas com executivos que atuaram na África no período mencionado, além de especialistas em comércio exterior, constatou-se que nos anos mencionados o governo brasileiro concedeu generosos incentivos aos empreendimentos direcionados para o mercado africano. Com o fim dessa política privilegiada, muitas empresas fracassaram, no entanto algumas permanecem em atividade, a exemplo da Câmara de Comércio Afro-Brasileira e da Construtora Norberto Odebrecht cujas trajetórias proporcionaram a entrada de outras empresas brasileiras no mercado africano, além de propiciarem importantes lições a empreendedores que desejam iniciar negócios no mercado africano. Concluímos que, a despeito da redução do apoio estatal e das mudanças no ambiente econômico interno e externo brasileiro, as oportunidades comerciais no continente africano existem e não podem ser ignoradas pelos homens de negócios, que tendem a julgar a África como um todo em função dos aspectos negativos ressaltados pela imprensa, da mesma forma que muitos empresários africanos desconhecem a qualidade dos nossos produtos e serviços.

\section{Abstract}

This article brings some reflections about the presence of Brazilian enterprises in the African market, focusing particularly the vision of different authors that had studied the trade relationship between Brazil and Africa. The text aims to answer two main questions. Firstly, under what motivations the Brazil-Africa trade obtained a notable growth between the 70's and the 90's? Secondly, what are the 
perspectives to the Brazilian entrepreneurs that want to begin a new business in Africa? Through bibliographical research and interviews with businessmen that worked in Africa in the mentioned period and with foreign trade specialists, it was found that in the mentioned years the Brazilian government gave generous incentives to the entrepreneurship directed to the African market. With the end of this privileging policy, many firms failed, nevertheless some of them are still active, for instance the Afro-Brazilian Chamber of Commerce and the construction company Norberto Odebrecht, whose trajectories propitiated the entry of other Brazilian enterprises in the African market. Besides that, they propitiate important lessons to the entrepreneurs that wish to initiate a business in the African market. We conclude that, in spite of the reduction of the state support and the changes in the Brazilian internal and external economic context, the commercial opportunities in the African continent exist and can not be ignored by the businessmen, that tend to judge Africa as a whole by its negative aspects, which are stressed by the media, in the same way that many African businessmen are unaware of the quality of the Brazilian products and services.

Palavras-chave: Comércio Brasil-África; Relações Econômicas Internacionais; Comércio Exterior.

Keywords: Brazil-Africa Trade; International Economic Relations; Foreign Trade. 